\title{
Development of Speaking System for Dumb People by Using Hand Gestures
}

\author{
Farida K. Kalonda ${ }^{1}$ and Stanley Leonard ${ }^{2}$ \\ ${ }^{1}$ Undergraduate Student and ${ }^{2}$ Assistant Lecturer \\ Mbeya University of Science and Technology \\ Tanzania
}

\begin{abstract}
It is very difficult for the voice impaired people to convey their messages to regular people since regular people are not trained on hand sign language, communication becomes very difficult. Therefore, I propose a speaking system that will enable dumb and deaf people to deliver their messages to normal people using hand gestures.

This proposed system, use of hand gestures reading system equipped with gestures and flex sensors connected to each finger and connected to the RF Transmitter as an input along with the speaker unit. This system powered by a battery-powered circuitry to run it. Also, this system will contain different words and sentences that will help dumb people to deliver basic messages. The system reads a dumb person's hand gesture for different variations of hand movement. A processor constantly receives input sensor values and then processes it, then searches for matching message for the set of sensor values. Once it found in memory, the message is retrieved and is spoken out using text to speech processing through the interfaced speaker [1]. Data for this study was collected using structured open and closed questionnaires which were clearly administered to the sample used in my study. Data were analyzed using embedded $C$ software. Finally, the findings were positive to my research objectives and it was expected to help the intended group in the society.
\end{abstract}

Key words: Flex Sensors, RF Transmitter, Speaker, Hand Gestures, Battery Powered Circuitry.

\subsection{INTRODUCTION}

The need of this system is to give output in day to day life for "Speaking system for Dumb People by using hand gestures". It will explain the aim and whole declaration for the evaluation of system. It will also explain system constraints, interface and interactions with other external applications. An attempt has also been made to explore about the need and motivation for interpreting ASL, which will provide opportunities for hearing impaired people in industry. This project is developed for the physically impaired people and would be beneficial as they can communicate with everyone. In this system a glove which is embedded with sensors will be wearied by physically impaired person, the physically impaired person will give a gesture. When he makes the gestures, it will be captured the exact positions of the finger. The captured gesture will be mapped with the one previously stored and accordingly exact gesture from the database will be identified. Continuing in this way physically impaired person will be able to go along the entire sentence that he wants to communicate. Later on this sentence will be translated into speech so that it would be audible to everyone through interfaced speaker. By using this system, the physically impaired people would be benefited as they can communicate with everyone freely which indeed would be great achievement for the mankind [2].

\subsection{Problem Statement}

In Tanzania about 34 million people are physical impaired [3] since it has been difficult for the voice impaired people to deliver their messages to regular people, there is a time a dumb person needs help from regular person or vice versa, but the way to communicate become barrier. This may be due to the lack of education about sign languages to the regular people, mute people fails to deliver their messages to the regular people and misunderstanding between sound impaired person and regular people.

\subsection{LITERATURE REVIEW}

In this research of designing a system that will help dumb people to communicate in our surroundings. This research proposal is based on a very simple concept whereby we need to have a means for capturing the sign languages available in order to utilize 
them to solve the presented problem above, meaning using to translate them into speech so that voice impaired people can communicate.

As a precursor to this research there have been many research involving simply of communication to dumb people. For example, in the research of Sign language, a language through which communication is possible without the means of acoustic sounds. Also is an effective tool that allows mute people to communicate with their non-mute counterpart. However, hand gestures are still not the most natural mode of communication and non-mute people still find it difficult to adapt to audio-less communication [4].

As well as in the research of electronic voice to deaf \& dumb people using flex sensor, a system facilitates individuals by means of a glove based mostly deaf-mute communication interpreter system. The glove is internally equipped with four flex sensors. For every specific gesture, the flex detector produces a proportional amendment in resistance and measures the orientation of hand. The process of those hand gestures is finished in controller. The glove includes 2 modes of operation- coaching mode to learn of each user associate degree an operational mode. The concatenation of letters to create words is additionally drained controller. Additionally, the system conjointly includes a Text to Speech conversion (TTS) block that interprets the matched gestures i.e. text to voice output [5].

Also in the research of image processing based speaking system for mute people using hand gestures, a system which would enable the dumb people to communicate with each and every one. In this system a webcam is placed in front of the physically impaired person.

The physically impaired person would put his finger in front of the web camera and the webcam will capture the hand gesture and perform image processing using principle component analysis algorithm (PCA).

The co-ordinates captured will be mapped with the one previously stored and accordingly exact picture from the database will be identified. Continuing in this way physically impaired person will be able to go through the entire sentence that he wants to communicate. Later on this sentence will be translated into speech so that it would be audible to everyone [2].

As well as in the research of Detection of Finger Motion using Flex Sensor for Assisting Speech Impaired, this paper is mainly focused on aiding the speech impaired and paralyzed patients. Our work helps in improving the communication with the deaf and dumb using flex sensor technology. A system is developed that can translate different signs including Indian sign language to corresponding text. About 9 billion people in the world come into this category which is quite large number to be ignored. Flex sensors placed on hand gloves pick up gestures and translate that to text data with the help of Analog to Digital convertor and microcontrollers. The main aim of the system is to develop a cheap glove that disabled people can use for communication. When the gesture of an alphabet is made respective alphabet is shown in the LCD. Sign language is prevalent amongst the deaf, dumb or blind individuals. With the conventional sign language not acknowledged to the signers, it affects their interpersonal relationships in the society in an adverse manner. A sophisticated method is required as deaf-dumb people use sign language for their communication which is difficult to understand by the normal people [6].

\subsection{Research Significance}

i. It will help to bridge communication gap between regular people and voice impaired people.

ii. It will help people with voice problem to get help as soon as needed from regular people.

iii. It will help those people with voice problem to interact with the society.

iv. It will help those voice impaired people who are studying to learn new things and enable them to ask and answer questions.

v. It will give a comfort to those voice impaired people to not feel discriminated.

\subsection{RESEARCH OBJECTIVE}

\subsection{Main Objective}

To implement a speaking system for dumb people by using hand gestures.

\subsection{Specific Objectives}

i. To design the circuit for actual glove.

ii. To calibrate the sensor.

iii. To measure the sensor responses for various gestures.

iv. To record the data sets for training the software.

v. To develop a prototype

vi. To test the prototype 


\subsection{Scope and Limitation of the Research}

Research is completed when all the research activities have been carried out and the objectives met [7]. As a final product of my research, the fully working system after meeting the objectives and also met the stakeholders' expectations submitted. The proposed system will be beneficial to voice impaired people as a reason to bridge the communication gap with their fellows who are normal, since communication is very important. Therefore, inability for the dumb and deaf people to deliver their message or effective communication, will be simplified to minimum.

\subsection{METHODOLOGY}

Data for this study were collected from the population of about 26. The case study was at Ikuti in Iyunga ward at Mbeya municipal. Structured and semi structured questionnaires were used as a data collection tool to administer the sample. However, interview was also used as a tool to collect data during my study. The questionnaire was designed to focus and answer the research objectives. For qualitative data an open ended questionnaire was developed to seek respondent's attitudes, views and behaviours on speaking system for dumb people. Closed ended questions provide the participants with several answers from which they could chose while an open ended questions gave participants freedom to answer the questions in any manner they chose [8]. The study also uses Slovin's formula [8] to compute the sample size of about 24 which was enough to represent the selected population of my study.

Data collection allows us to collect information that we want to collect about our study object. Depending on my research type, any tool can be used. In my project I choose to use Questionnaire as data collecting tools. As the sample size, the lesser the probability that findings will be biased does hold, diminishing returns can quickly set in when samples get over a specific size which need to be balanced against the researcher's resources.

\subsection{Data Analysis and System design}

The aim of design of any kind of a system is to make sure that, the system is explained in terms of its behaviour, structure and interaction with external entities [9]. The modern approach chosen to explain the interaction and behaviour of my research. By considering statistical above, the following is the histogram of sample questions of my research.

\section{Do you get any obstacle while communicating to regular people?}

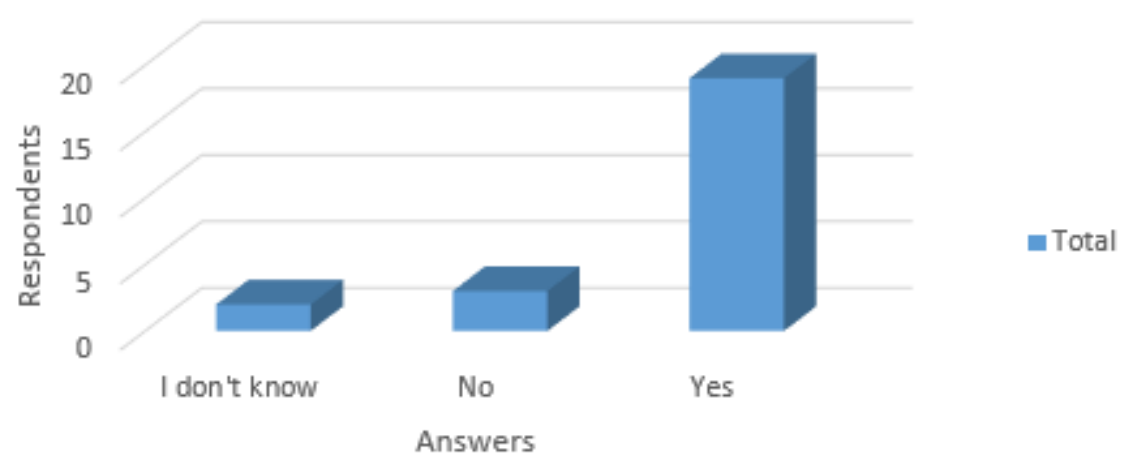

Figure 1: Histogram for sample question one 


\section{Which language do you use to communicate to regular people?}

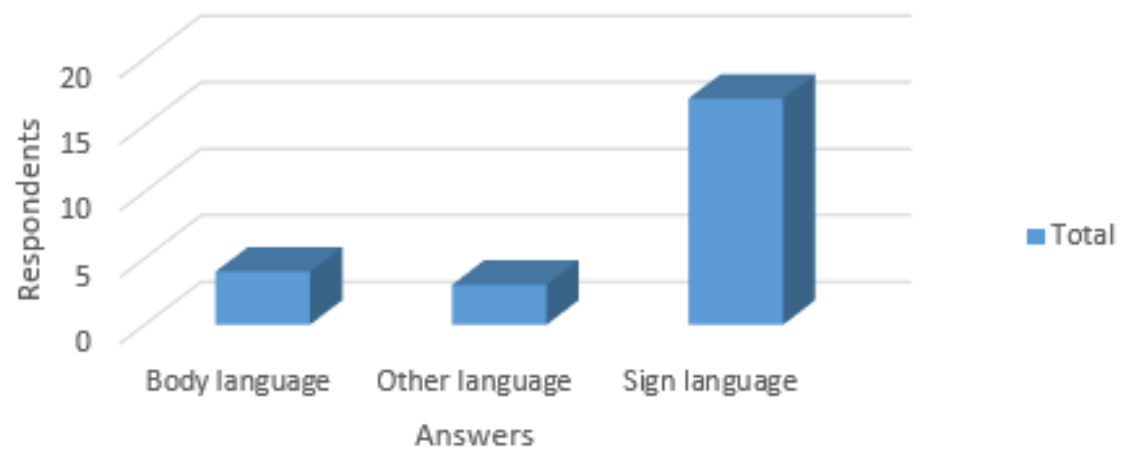

Figure 2: Histogram for sample question two

The modern way of designing was used and the following diagrams were modelled using Unified Modelling Language (UML).
i. $\quad$ Block diagram
ii. Use case diagram

Block diagram of the research

This is a graphical language explaining about the structure of the system from the input to the output as well as the functions of the particular system.

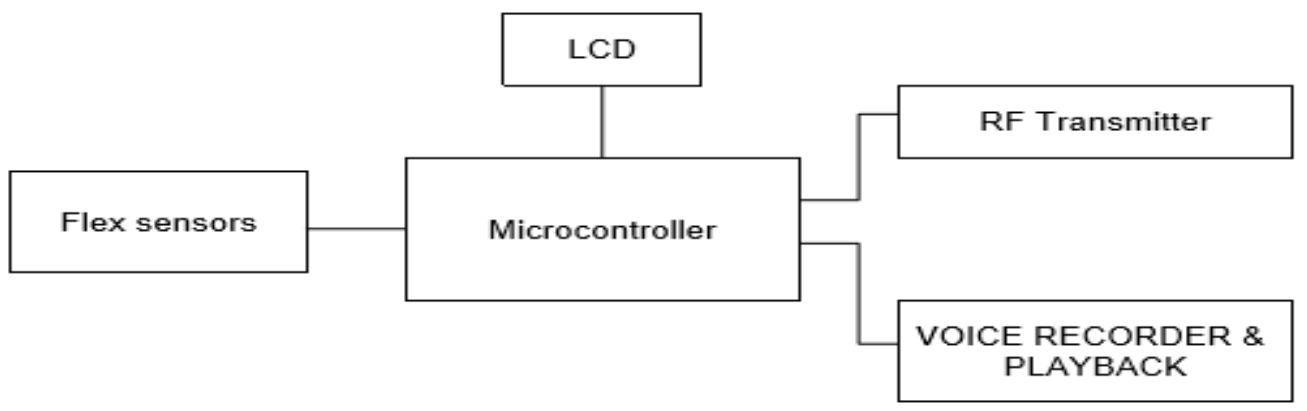

Figure 3: Block diagram

Use case diagram

These kinds of diagram explain about the interaction of my system with some of the external entities that are part of my system, explaining how they communicate. 


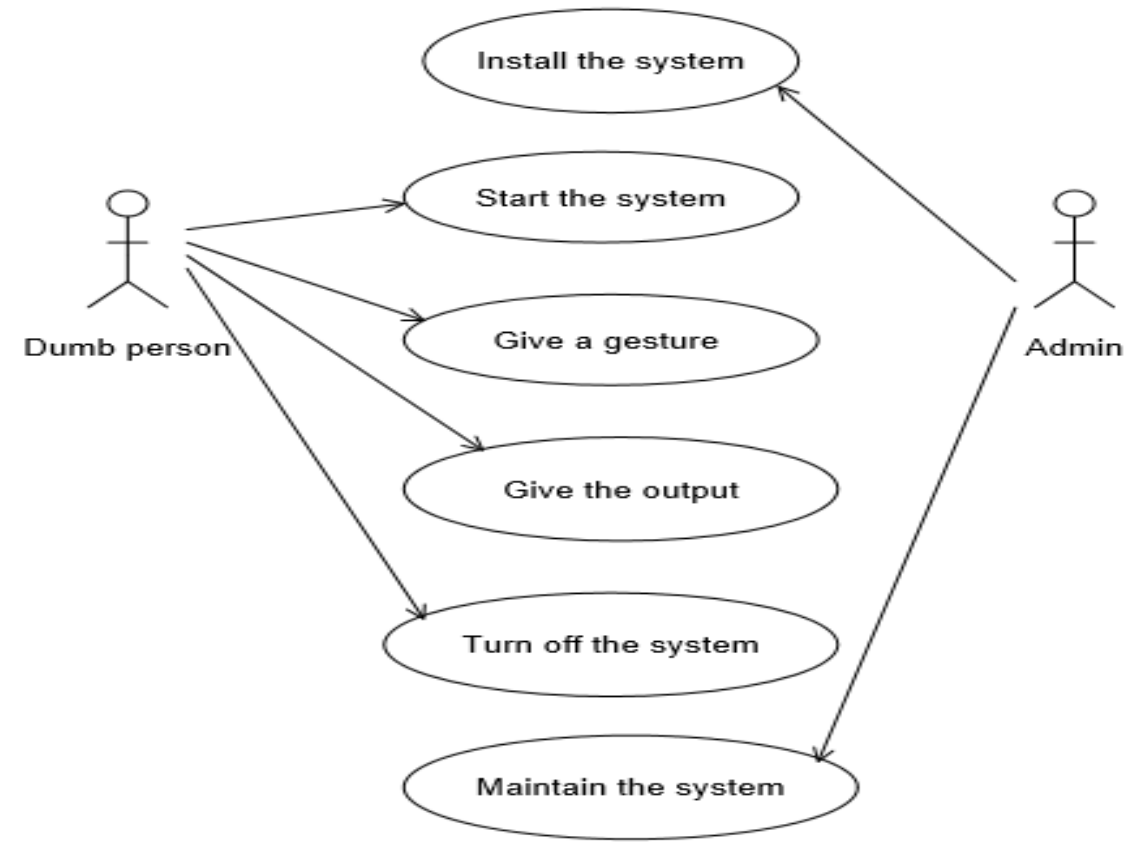

Figure 4: Use case diagram

The circuit design and Simulation using Altium designer software.

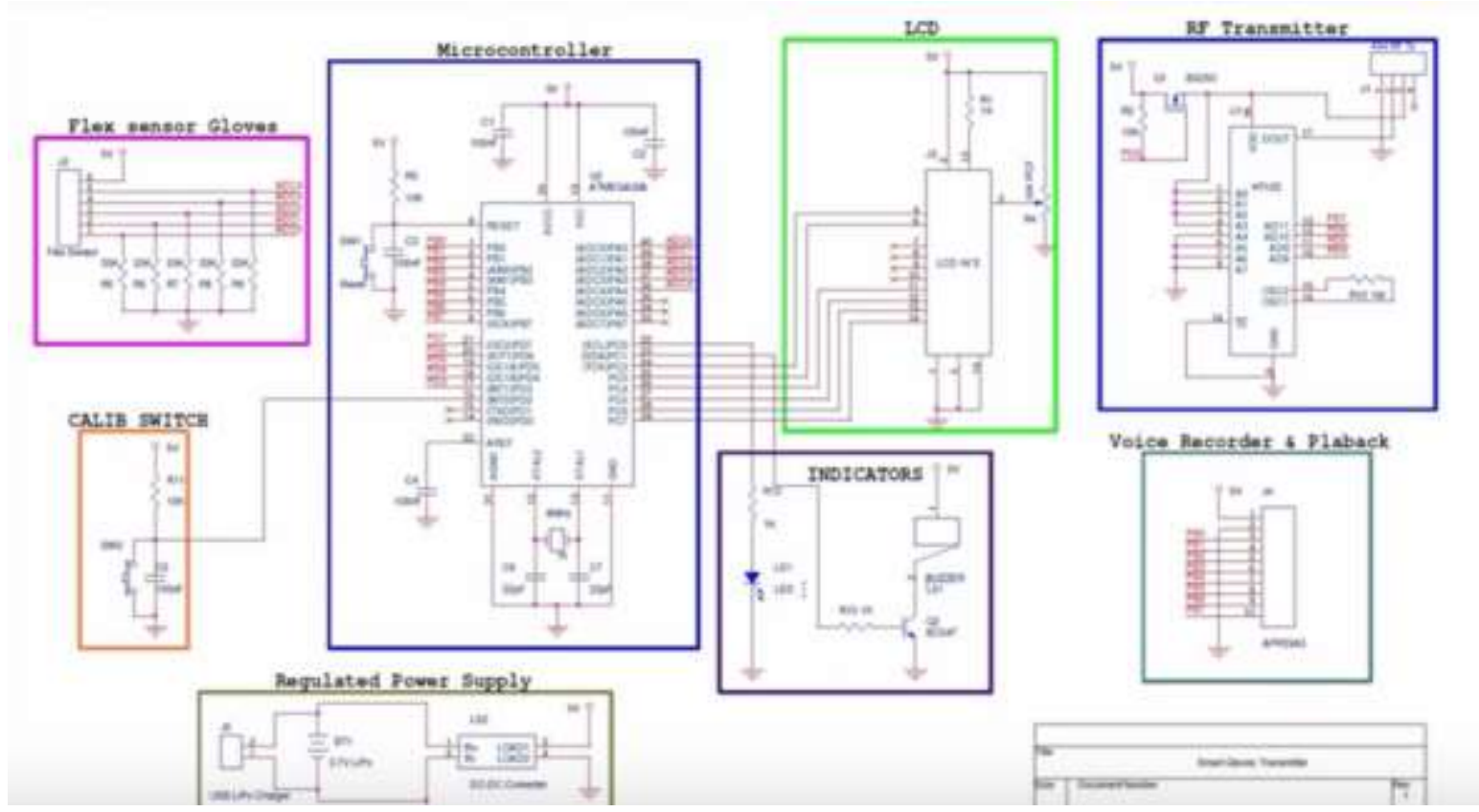

Figure 5: Circuit diagram

\subsection{The Prototype Designing}

The system makes use of a hand motion reading system equipped with motion and flex sensors along with a speaker unit. This system is powered by a battery powered circuitry to run it. Arduino Uno is used for processing the data and operating the system. The system consists of several stored messages like, that help mute people convey basic messages. The system reads person's hand motions for different variations of hand movement. The Arduino Uno processor constantly receives input sensor values and then processes it. Now it searches for matching messages for the set of sensor values. Once it is found in memory, this messages are retrieved and spoken out using text to speech processing through the interfaced speaker.

The components used for the prototype build up where as listed in table 1 . 
Table 1: Components summary

\begin{tabular}{|c|c|}
\hline Component & Specification \\
\hline Flex sensors 5 unit & 4.5 " length \\
\hline Speaker 1 unit & $90 \mathrm{Db} / 2.83$ volts \\
\hline $\begin{array}{c}\text { Audio processor store and sound } \\
\text { playback }\end{array}$ & APR33A \\
\hline Transmitter and Receiver & 434MHz RF \\
\hline Microcontroller & ATmega32A \\
\hline
\end{tabular}

\subsection{SUMMARY OF RESULTS}

As stated above, from the analysis software output most of the individuals requires some changes regarding to speaking systems which the idea of this research was to offer the solution to the stated problem that faces the community.

\subsection{RECOMMENDATION}

As suggestion, my research is not suitable for Android, therefore I suggest the following:

i. To improvise the portability, an Android application can be developed for displaying the text and speech output on an Android device so that will also be help of developing mobile communication for voice impaired people.

ii. Also this system has mostly based on American Sign Language but another system can be developed for different sign languages.

iii. To develop more portable system which will be helpful for even children with the voice impaired.

iv. Also will help to develop a system that will consist of trigger sensor in order to indicate that the system has to be activated and a person want to speak something, this to ensure that the system does not speak when the person is just involuntarily making hand motion.

\section{List of Abbreviations}

MUST - Mbeya University of Science and technology.

ASL - American Sign Language.

TTS - Text to Speech.

PCA -Principle Component Analysis.

RF - Radio Frequency

\section{BIBLIOGRAPHY}

[1] NevonProject, "NevonProjects," 2018. [Online]. Available: http://nevonprojects-com.cdn.ampproject.org.

[2] Jain, Jain, Sharma and Chauhan, "INTERNATIONALUOURNAL OF ENGINEERING SCIENCE \& RESEARCH," IMAGE PROCESSING BASED SPEAKING SYSTEM FOR MUTE PEOPLE USING HAND GESTURES , 2018.

[3] "who," 2019. [Online]. Available: http://www.who.com.

[4] Priya, Siddhart, Karan and Adtya, "International Journal of Innovative Research in Computer and Communication Engineering," Meri Awaaz - Smart glove learning Assistant for Mute students and teachers, 2017.

[5] Praveen and Prasad, "International Journal of Innovative Research in Computer and Communication 
International Journal of Engineering Research And Advanced Technology, Vol.5, Issue 8, August-2019

engineering," Electronic Voice to Deaf \& Dumb People Using Flex Sensor , 2016.

[6] . H. Joshi, S. Bhati, K. Sharma and V. Matai, "International Journal of Innovative Research in Science, Engineering and Technology," Detection of Finger Motion using Flex Sensor for Assisting Speech Impaired, 2017.

[7] J. Kusar, L. Bradesco, J. Duhovnik and M. Starbek, Project Management of Product Development, 2008.

[8] M. K, D. D and F. D, "Essentials of research design and methodology," 2005.

[9] J. W. Creswell, "Research design:Qualitative, Quantitative and mixed methods," 2014.

[10] Kumar, RESEARCH METHODOLOGY, 2011.

[11] Yanfika, "International Journal of social Science andEconomic Research," WORKERS PERFORMANCE FROM PERSPECTIVE OF PROFIT, QUALITY AND WORK ACCURACY IN TRADITIONAL FISHERY BUSINESS IN LAMPUNG PROVINCE, 2018. 